\title{
Current Status and Policy Implications for Fostering Social Entrepreneur
}

\author{
${ }^{1}$ Yoon-Doo Kim and ${ }^{2}$ Seok Yoon \\ ${ }^{1}$ Department of Food Resources and Environment Economics, \\ Konkuk University, 322 Danwol-Dong, Chungju-Si, Chungcheonbuk-Do, 380-701, Korea \\ ${ }^{2}$ Department of Social Entreprise, Graduate School of Business Administration, \\ Gachon University, 1342 SeongnamDaero Sujeong-Gu, Seongnam-si, Gyeonggi-do 461-701, Korea
}

\begin{abstract}
In this study, problems in current status of social entrepreneurs in Korea were examined and further policy issues for them were suggested as well. For the methodology, the study analyzed the drawbacks and policy implication of fostering social entrepreneurs through Focus Group Interview (FGI) on analysis of present condition of incubating social entrepreneur and programs for it. First, it should escape from personnel expense-centered one and convert to ecosystem-centered or division-centered project in the direction of the government for fostering social entrepreneurs, putting emphasis on follow-up management and evaluation. Second, it must suggest a standard model for social entrepreneur promotion project. In other words, the projects with low performance should be reduced and education models appropriate for new circumstances and changes must be adopted through not only programs standardized in divisions, categories and local provinces, but also appointing expert instructors and project evaluation. Third, it's necessary to propose specific guideline for detailed education operation according to education trainee and objectives of social entrepreneur. Fourth, it is needed to have more various contents development and distribution by strengthening support for specialized foundation, management and case studies related to fostering social entrepreneurs. Finally, it is even more required to spread awareness on social economics relating to programs for fostering social entrepreneur. With the long-term perspective, it is needed to render policy and specialization for fostering Korean-model social entrepreneurs, which is able to raise competent social entrepreneurs suitable for each stage of growth such as sourcing, incubation and launching social entrepreneurs.
\end{abstract}

Keywords: Social Enterprise, Social Entrepreneurs, Social Entrepreneurship, South Korea

\section{INTRODUCTION}

Social enterprise has been started in Europe, which has long socialistic tradition since 1970. The reason the social enterprise emerged was that since growth target for profit seeking was the first priority at that time, it can be said that the governments' intervention in the marketplace or an entrepreneurial spirit could not make motivation for social service or realizing social values; non-profit organizations, therefore, provide social service which could not be served by businesses or states.

Recently, as the competition in labor market is intensified, social service is developing into creating jobs for the vulnerable, social integration and providing service social community needs and making work pay. The development of social businesses until now can be said that it has been in compression increase in a speed because of know-how accumulated in economic growth process and strong demand for welfare pluralism.

In Korea, it's since so-called IMF financial crisis when the discussion about social enterprises has begun. Although the policy of creating employment through the government's funding as one of means to overcome the financial crisis was somewhat effective, since 2000, the debate on introduction of social enterprises from Europe has been progressing briskly because of Europe has been progressing briskitionment Economics, Konkuk University, 322 Danwol-Dong, Chungju-Si, Chungcheonbuk-Do, 380-701, Korea Tel: +82 438403565 Fax: +82 226406888 
structurization of growth without employment and increase of demand for social service.

In this process, the Social Enterprise Promotion Act (July 2007) was introduced and the project of social employment created profits, beginning to achieve some fruitful outcomes as a model to look after independence through the enforcement of the Act. In other words, the policy of social enterprise means that the government leadingly decides the order of priority of policies and carries out the project of fostering and activation of social enterprises through the funding. As a result, for the economic effect through the Social Enterprise Promotion Act, the number of authorized social enterprises is 565 (as of the end of September 2011), the employees working in social businesses as a whole are approximately 15,000 and the vulnerable among them are over 9,000 (MEL, 2011).

The market performance achieved by only 5 years was remarkable and it can be evaluated that the government's leading policy was effective in the first place.

On the other hand, there was the controversy of 'wasting money,' (SN, 2011) which could be side effect before settling the system. In other words, once the budget support for business related with creating jobs was finished, the comments on the fact that it was wasting budget due to cancellation of employment and lack of follow-up management came out.

However, it's too early to estimate that the government's policy has gone wrong, because in Europe or US in which social enterprises are advanced, it took a long time to establish market-led or the government-led settlement of the system (Odgen-Newton, 2010). Above all things, it's important to improve problems in operation of the institution for social enterprises to have competence, but ultimately, it's the most important to foster social entrepreneurs who can be said to be engines of growth. This study will look at constructing of training system for social entrepreneurs who are equipped with expertise and management ability to run social enterprises and the present status and problems of fostering social entrepreneurs which can support the above, then go to suggest further policy implications for fostering social entrepreneurs.

For the method of this study, the current status of fostering of social entrepreneurs in Korea will be analyzed. For in-depth study, particularly, this study will suggest problems and policy issues of incubating of social entrepreneur through Focus Group Interview (FGI) on the program of social entrepreneur promotion.
In the course of this study, it will be found that the development for programs and manual which raise social entrepreneurs is needed and standard model for fostering social entrepreneur must be presented. Therefore, it is expected that the result of this study may be a basic material to suggest measures of support and policy direction for bureaucracy involved in social entrepreneurs.

\section{MATERIALS AND METHODS}

For the method of this study, the current status of fostering of social entrepreneurs in Korea will be analyzed. For in-depth study, particularly, this study will suggest problems and policy issues of promotion of social entrepreneur through Focus Group Interview (FGI) on the program of social entrepreneur promotion.

\subsection{Current Status of Fostering Social Entrepreneur}

According to Schumpeter (1994), an entrepreneur is defined as an innovative subject who continues to lead the process of creative destruction. In other words, it's not entrepreneurialism to merely found and run a new business in a market. Thus, social entrepreneur can't be said to do a role as he or she simply runs a social business.

Social entrepreneurs, therefore, are not the enterprisers who pursue economic rationality which is the maximization of wealth, but the ones who seek for social rationality, the maximization of social values, becoming the social change agents with the characteristics of social workers in order to accomplish social commitment. A social entrepreneur can be defined as the one who utilizes the principle of corporate management and has entrepreneurial goals which pursue economic rationality of undertaking for profit and the objective of economic and social rationality at the same time. Likewise, social entrepreneurs are not considered to manifest the spirit of social entrepreneur even when they found and run all non-profit organizations.

In fact, a social entrepreneur can be the greatest parameter that makes or breaks the social enterprise. Though success or failure of policy undertaking is determined by capability of the policy conductors, social entrepreneur's role is more important in the condition that consciousness of social economy is lacking (MEL, 2010a). In the success or failure rate of social enterprises, therefore, not only the role of social entrepreneurs as the main agents for pushing policy, but also fostering human resource of enterprisers who have entrepreneurial spirits as social entrepreneurs has significance. 
It's needed that the low productivity of social enterprises must be overcome and promotion of social entrepreneurs is necessary for activating support for social enterprises through innovation of governmentsupporting system. In other words, in order to promote social enterprises, expansion of base and reinforcement of human base through incubating social entrepreneur (MEL, 2010b). Also, it's necessary to create pan-national bond of sympathy on values and roles of social enterprises through public relations of them by using a variety of media.

The education program for fostering social entrepreneur can be largely divided into three: first, academy business; second, young-adults academy business; third, social venture business. Among these three projects, academy and young adults academy projects raise social entrepreneurs with creative management ability and the social venture business excavates and supports those social entrepreneurs.

In the budget for social enterprise promotion in 2011 (9.44 billion won; KRW), the calculated fund for incubating social entrepreneurs takes up about $15 \%$ of all budget for social enterprises including social entrepreneur academy, fostering social entrepreneur such as young adults, social venture competitions, evaluation and monitoring. This can be found in Table 1.

Among them, it can be noticed that the budget for fostering social entrepreneur including young adults takes up 1.12 billion won, the largest amount. This means that the government carries it forward as a typical project for promoting social entrepreneurs with creative ideas and foundation of the rising generation.

\subsection{Social Entrepreneur Academy}

The operating purpose of social entrepreneur academy is to foster social entrepreneur equipped with vision, talent, innovative ideas and management skills for independence and sustainable growth for social enterprise. Also, the purpose is to maximize business performance and ultimately contribute to developing as a sustainable social enterprise.

As shown in Table 2, the education condition for social entrepreneur academy is composed of introduction to foundation course, business management course for executives and reinforcing the capability of hands-on worker course.

The introduction to foundation course is designed for ordinary people to learn about founding, understanding social enterprise and cultivation of value and supporting on-the-job training necessary for actual founding through educations such as screening and evaluation by using (preliminary) report generation on founding. This introductory course for establishment progresses in 8 educational institutions (4 in capital area and 4 in the regions) as general operating agencies, spreading the values of social enterprises and rearing potential preparatory social entrepreneurs.

The business management course for executives is the program aimed at Chief Executive Officers (CEO) of social enterprises. The education has its objectives in in-depth understanding the principles of corporate management, training management professionals who can plan new projects and lead business innovation to foster social entrepreneurs with sustainable management capability.

The reinforcing the capability of working-level course is the education program that maximizes the ability of hand-on workers of social enterprises through trainings on banking, financial accounting and marketing for 8 rage spheres nationwide and specialized education for two categories of business (cleaning and car wash and trip to process). Especially, this course proceeds in the purpose of training competent hands-on staff for social enterprise through education of working-level parts of social enterprise including management skills and individualized education for industrial classifications.

Young adult social entrepreneur promotion undertaking: In order to fostering social enterprises, it's needed to activate social businesses by using creativity of the rising generation of all things. Also, through the participation of those young adults, youth and general public with creative ideas and challenging spirits' interests in social enterprises must be promoted to discover models for sustainable and competent social enterprises.

In addition, it is for young adults to establish social enterprises by supporting space, funding and mentor needed for founding social businesses and giving operating agencies which possess various infrastructures related with founding and fostering social enterprises.

First, as an implementation system for nurturing social entrepreneur and founding among young adults, the government recruits establishment teams and provides them with working space and activity cost necessary for founding, supporting creative and developmental businesses, as in Fig. 1. 
Table 1. Budget execution in 2011 (As of October 18, 2011) (Unit: Million won)

\begin{tabular}{lccc}
\hline Category & Budget (A) & Executed (B) & Execution rate (B/A, \%) \\
\hline Subtotal & 16,165 & 7,938 & 49.1 \\
- Fostering social entrepreneurs including young adults & 11,200 & 5,154 & 46.0 \\
- Social venture competition & 910 & 422 & 46.4 \\
- Network establishment & 300 & 187 & 62.3 \\
- Social Entrepreneur Academy & 735 & 315 & 42.9 \\
- Evaluation and monitoring & 300 & 113 & 37.7 \\
- Social Enterprise Public Relations and Hanmadang Event & 555 & 344 & 62.0 \\
- Operating Social Enterprise Promotion Agency & 2,165 & 1,403 & 64.8
\end{tabular}

Source: KSEPA (2011)

Table 2. Educational status for social entrepreneur academy in 2011

\begin{tabular}{lllll}
\hline Curriculum & Subject & $\begin{array}{l}\text { The number of } \\
\text { people aimed }\end{array}$ & $\begin{array}{l}\text { The number of } \\
\text { lecture time } \\
\text { (Opening of class) }\end{array}$ & Educational contents \\
\hline $\begin{array}{l}\text { Introduction to foundation } \\
\text { (8 branches) }\end{array}$ & General Public & $300 \sim 400$ & $30-60 \mathrm{~h}$ each & $\begin{array}{l}\text { Founding guide, understanding of social } \\
\text { enterprises and value cultivation }\end{array}$ \\
$\begin{array}{l}\text { Business management } \\
\text { course for executive } \\
\text { enterprises (1 institution) }\end{array}$ & CEOs of social & $30 \sim 40$ & Approx. $100 \mathrm{~h}$ & $\begin{array}{l}\text { Learning throughout management in general } \\
\text { (cast studies, conducting projects) }\end{array}$ \\
$\begin{array}{l}\text { Reinforcing capability of } \\
\text { hands-on workers }\end{array}$ & $\begin{array}{l}\text { Hands-on workers } \\
\text { in social enterprises }\end{array}$ & $200 \sim 300$ & $\begin{array}{l}2040 \text { hours each } \\
\text { (8 rage spheres, } 2\end{array}$ & $\begin{array}{l}\text { Corporate management(finance, accounting } \\
\text { and marketing) Specialized education } \\
\text { types of business) }\end{array}$ \\
\hline \begin{tabular}{l} 
for industrial classifications \\
\hline
\end{tabular} & & & &
\end{tabular}

Source: KSEPA (2011)

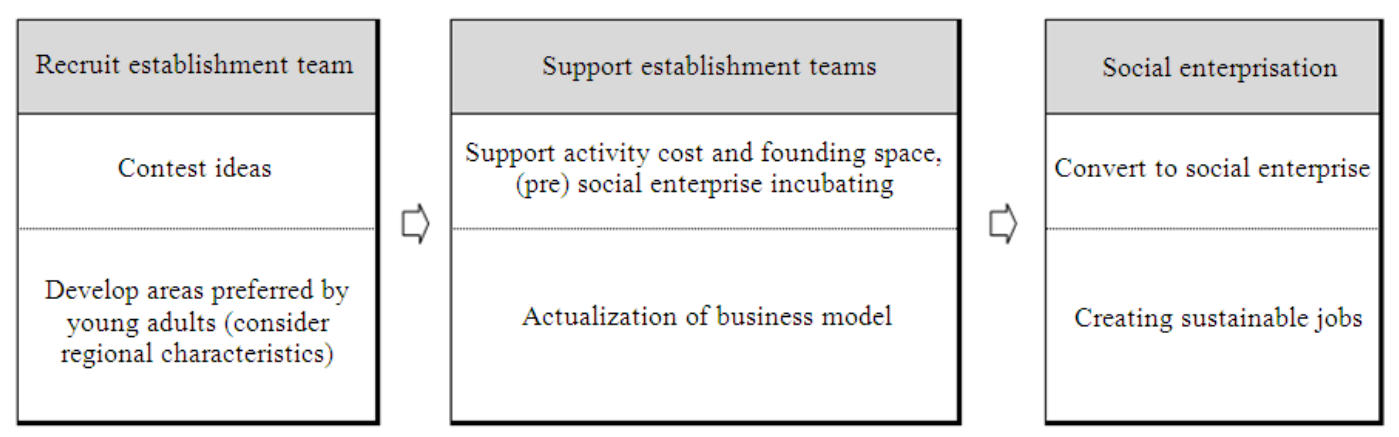

Fig. 1. Implementation system for promoting social entrepreneur among young adults

Therefore, the establishment teams can actualize business models and convert them into social enterprise, so that creating sustainable jobs can be possible. As an agency that takes charge of this study structure, Korea Social Enterprise Promotion Agency establishes detailed plans and supervises projects and commissioned operation agencies directly conduct the projects and take charge of consulting for management/founding and supporting working expenses, selecting applicants who have capability as social entrepreneurs and want to establish social enterprises.

The duty for fostering social entrepreneurs is controlled by Korea Social Enterprise Promotion Agency in general, but project teams contest ideas through business application and promotions as well as actualize business models and let commissioned operating agencies incubate and support establishment teams.

Second, support for working expenses can be divided into three parts: founding training and outside specialists matching costs, market cultivation and public relations costs and prototype production cost. Here, founding training and outside specialists matching costs are the expenses spent in receiving training in outside specialized agencies or utilizing outside experts; the market cultivation and public relation costs are spent in producing catalogues, media production, participating 
exhibitions and patent applications and obtaining various certifications; the prototype production cost is outsourcing and material expenses which are spent when consigning or requesting service to outside institutions for making samples and the working expenses are supported within 30 million won, considering the contents of projects according to differential rates. Also, as in Table 3, the current status of budget execution for promotion social entrepreneurs including young adults, its execution rate registers $46 \%$, somewhat low Fig. 2.

Third, Table $\mathbf{4}$ is the present condition of commissioned operating institutes for social enterprisers including young adults. As a specialized operating agency which retains infrastructures to promote young adult social enterprisers and activate founding, it designates 19 institutes for areas and industrial classifications and progress projects Fig. 3.

Besides, Korea Social Enterprise Promotion Agency has planned operation and designs for total 20 teams including Korea Association of Social Workers (7) and Head Flow inside within the Agency (13). In 2012, like 2011, the Agency set a goal of total 320 founding teams.

Fourth, as mentoring for fostering social enterprisers, the program reports consultations for management and foundation as well as provides the connection with experts (institutes) through full-time mentors to provide full-time mentor service in which young adults can receive consultation in the beginning of the establishment. Especially, it will operate mentoring system which can support through network with private or public sectors in social mission, clarification of business model, daily corporate management, constructing management system, connecting to resource for supporting a new business and public relations Fig. 4.

Finally, by taking monitoring and reviewing follow-up status centered on foundation teams and commissioned operating agencies, the agency inspects reports on project promotion (quarterly) from foundation teams and Korea Social Enterprise Promotion Agency receives mid-term reports from the commissioned operating institutes and review them again (open a debate), conducting on-site instruction through Korea Social Enterprise Promotion Agency and private cooperative agencies.

\subsection{Social Venture Business}

Social venture means business and enterpriser activities led by the one with creative entrepreneurship who challenges adventurous businesses. The social venture activities are widely operated to discover and foster social enterprisers. As such institutes, for example, Ashoka Fellow can be one of those institutes and Global
Social Venture Competitions (GSVC) are held (http://www. socialenterprise.or.kr).

In Korea, the government and private sectors encourage social venture activities by supporting discovering preliminary social enterprisers and a variety of competitions. Social Venture Competition, particularly, excavates creative business model through contests. Social venture businesses can be divided into nationwide and regional competitions. First of all, the nationwide events discover social business models through public relations for nationwide competitions and process of the final contest, supplementing the business plans to be site-centered ideas by providing mentoring. For those award-receiving teams, the agency spread their outstanding ideas to social enterprisers and participating institutes by prizes and follow-up control and producing and distribution of performance reports.

Second, the institutes which can carry out regional competitions effectively are selected and the institutes choose excellent ideas so that they can be actualized. Also, outstanding teams for each region are selected and rewarded in final results and supported to compete in national competitions.

The regional and national contests in 2001 progressed in adult and adolescent teams. In regional competitions, total 88 teams were selected (adults: 56 teams, adolescents: 32 teams) and growth contest exhibit was conducted for the national competition to select 31 teams total.

As in Table 5, support status for such social venture working expenses, the subjects to receive working expenses in foundation and idea parts were selected in 2009 and in 2010 and 2011, supports for young adults and adolescents were selected, expanding backing for social ventures.

In order to increase effectiveness of connection to social venture foundation and competitions, those who enter finals and win a prize in the contest should be connected to the program for fostering social enterpriser including young adults and methods for promoting business performance through evaluation of the performance must be devised.

The monitoring and follow-up management of social venture competitions until now have been satisfaction research of the competitions for those regional and national prize-winning teams in social venture competitions, monitoring through research on present situation of enterprise for previous awardwinning teams and conducting of follow-up control in order to improve related problems revealed in the operation of the competitions. 
Yoon-Doo Kim and Seok Yoon / American Journal of Economics and Business Administration 4 (3): 155-165, 2012

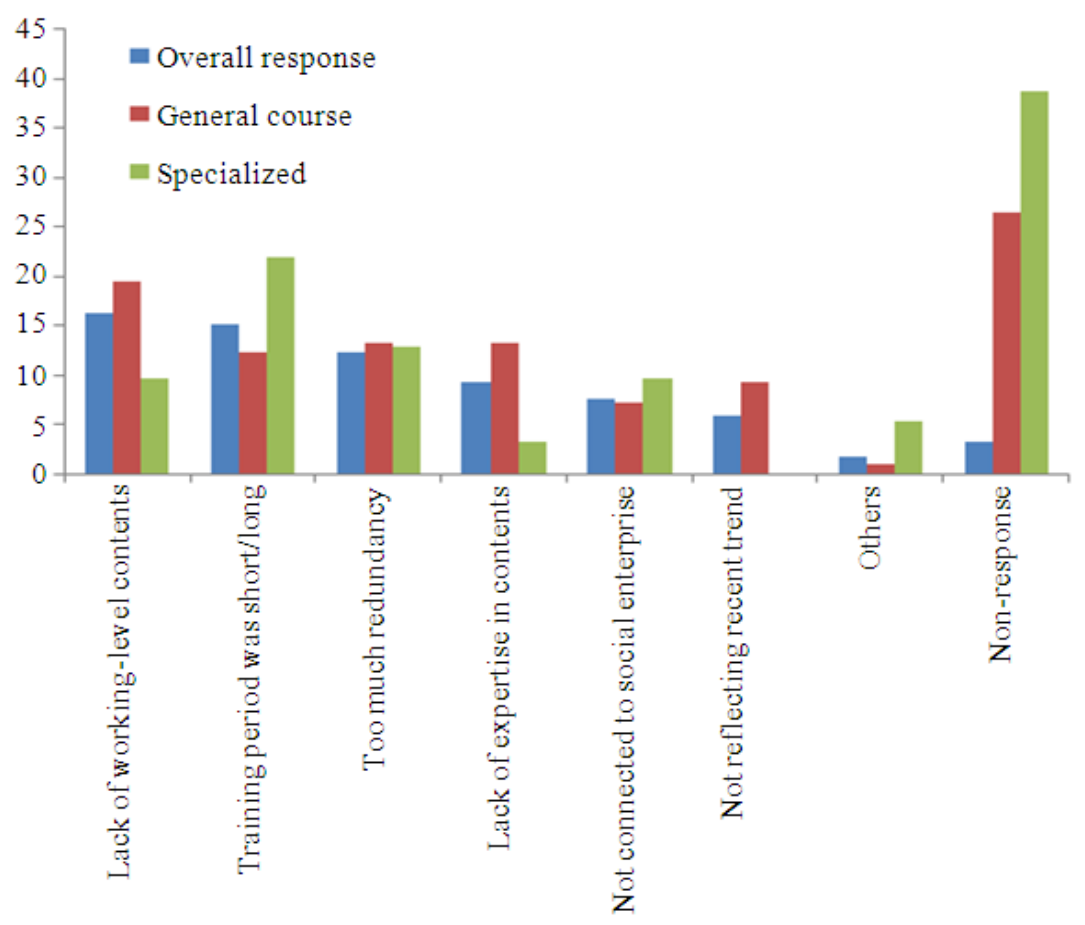

Fig. 2. Causes of dissatisfactions with curriculums (Unit: \%)

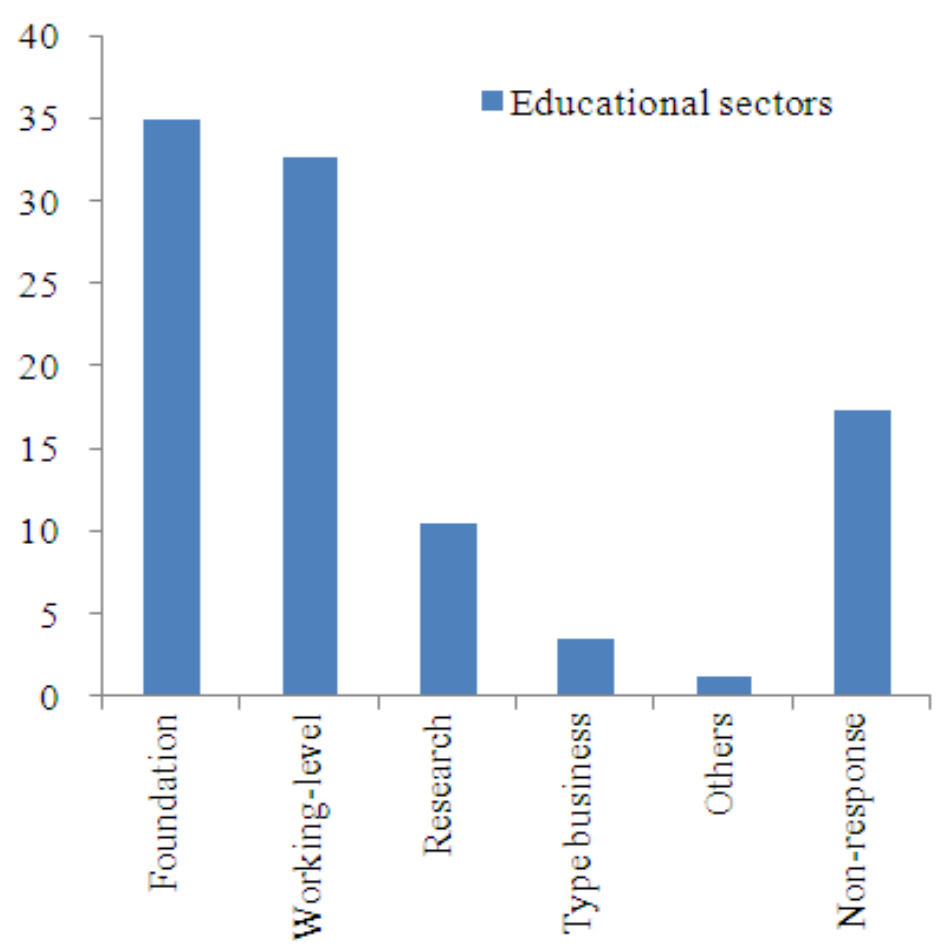

Fig. 3. Educational Sectors Trainees Want to Re-Take in the Future (Unit: \%) 


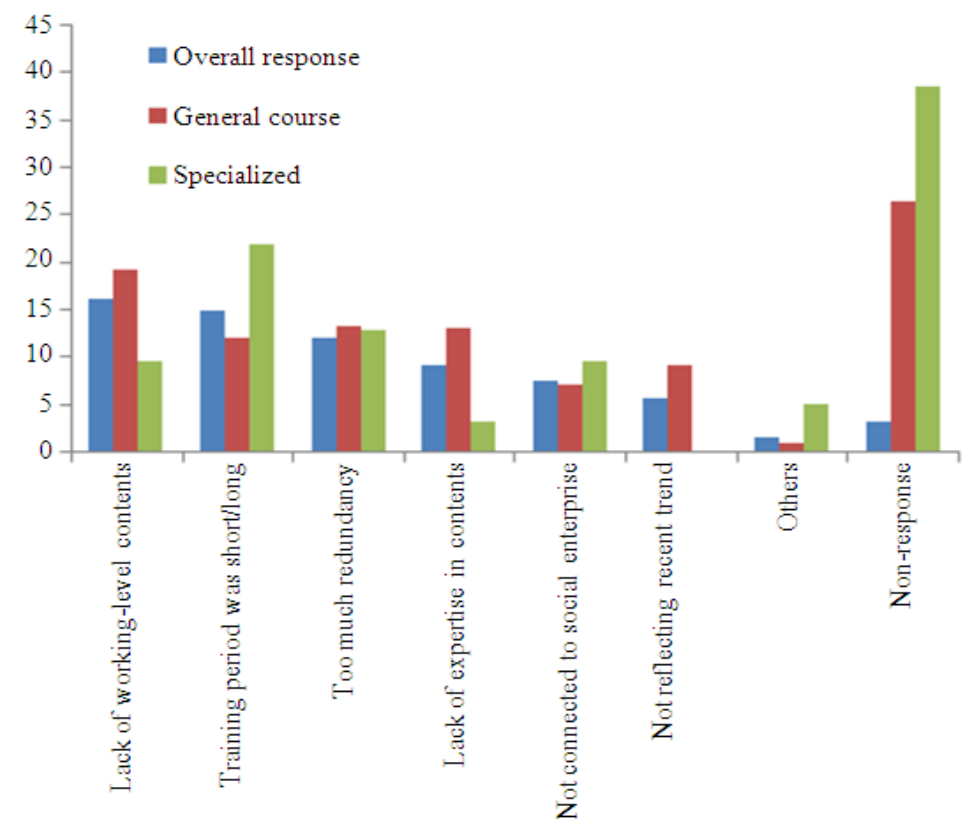

Fig. 4. Desires when taking expert courses in the future (Unit: \%)

Table 3. Budget execution in 2011 (As of Oct. 18, 2011) (Unit: Million won)

\begin{tabular}{llll}
\hline Category & Budget (A) & Executed Budget (B) & Execution Rate (B/A, \%) \\
\hline $\begin{array}{l}\text { Promoting social entrepreneurs } \\
\text { including young adults }\end{array}$ & 11,200 & 5,154 & 46.0 \\
\hline
\end{tabular}

Source: KSEPA (2011)

Table 4. Current Status of commissioned operating agencies for promotion of social entrepreneur including young adults in 2011 (As of October 17, 2011)

\begin{tabular}{|c|c|}
\hline Category & Name of Institutes \\
\hline \multicolumn{2}{|l|}{ Regions-16 } \\
\hline \multirow[t]{4}{*}{ Seoul $(4)$} & Social Enterprise Support Network \\
\hline & Seeds-Haja Center \\
\hline & The World We Make Together, Social Solidarity Bank \\
\hline & Work Together Foundation \\
\hline \multirow[t]{3}{*}{ Gyeonggi and Incheon (3) } & Gyeonggi Welfare Foundation-Dankuk University \\
\hline & Kyungwon University-Choongang University Consortium Agency \\
\hline & Yuhan College-Overcoming Unemployment Headquarters for Citizen's Campaign in Bucheon \\
\hline Gangwon (1) & Sangji University Educational-Industrial Complex \\
\hline \multirow[t]{3}{*}{ Chungcheong (3) } & Hoseo University Educational-Industrial Complex \\
\hline & The Grassroot People \\
\hline & First Institute of Management and Technology \\
\hline \multirow[t]{3}{*}{ Youngnam (3) } & Kyungnam University Educational-Industrial Complex \\
\hline & Kumoh National Institute of Technology-Educational-Industrial Complex Taegu Institute of Social Science \\
\hline & Research Institute for Social Enterprise \\
\hline \multirow[t]{2}{*}{ Honam (2) } & Jeollabuk-do Business Agency \\
\hline & Gwangju NGO Citizen's Foundation \\
\hline \multicolumn{2}{|l|}{ Industries-3 } \\
\hline Culture (1) & Keimyung University Educational-Industrial Complex \\
\hline Education (1) & People Who Make Happy Future Culture \\
\hline Women (1) & Ewha Women's University Research Institute for Management \\
\hline Total & 19 Institutes \\
\hline
\end{tabular}

Source: KSEPA (2011) 
Table 5. Support status of working expenses for social venture

\begin{tabular}{|c|c|c|}
\hline Year & Support status & $\begin{array}{l}\text { Support Fund } \\
\text { (Million won) }\end{array}$ \\
\hline 2009 & $\begin{array}{l}-7 \text { Teams in ideas sector and } 7 \text { teams in founding sectors were awarded } \\
\text { * Prize Money: Maximum of } 5 \text { million won in idea sector and } 30 \text { million won in founding sector } \\
\text { * Loan: supported } 600 \text { million won for award-winning teams by Korea Labor Welfare Corporation }\end{array}$ & 2,444 \\
\hline 2010 & $\begin{array}{l}\text { - } 10 \text { Teams in founding young adults sector, } 5 \text { teams in founding general sector and } 5 \text { teams in } \\
\text { idea sector were selected } \\
\text { * Prize Money: Maximum of } 5 \text { million won in idea sector and } 30 \text { million won in founding sector }\end{array}$ & 1,200 \\
\hline 2011 & $\begin{array}{l}\text { - } 18 \text { Teams in adolescent sector, } 25 \text { teams in adult sector } \\
\text { * Prize Money: Maximum of } 5 \text { million won and } 30 \text { million won in adult sector }\end{array}$ & 890 \\
\hline
\end{tabular}
Source: KSEPA (2011)

\subsection{Drawbacks in Fostering of Social Enterpreneur}

\subsubsection{The Problems of Policies for Social Enterprise}

The policy of social enterprise in Korea, in a word, can be said to have achieved a remarkable growth in a short period of time. That is, Social Enterprise Promotion Act was enacted and institutional supplementation was accomplished by completing ordinance for 16 cities and provinces in each region and type of business (Chang, 2010). Also, a specialized support agency which takes charge of activation of social enterprises was established, preparatory social enterprises were approved from each local government and market conditions which can inbreathe spirit of social entrepreneurship are created by selecting academy and commissioned education institutions for incubating social entrepreneurs.

However, quite a number of problems appear in such eye-opening growth process. In the governmentled policies, some problems that private or marketleading policies cannot be settled emerge. That is, the drawbacks come to the fore in the government policy towards social enterprises are summarized as follows (Kim, 2011a; 2011b).

First, the support for personnel expenses form up a great part in the project for creating jobs in social enterprises. That is, the weight of labor costs in total supports was high, registering $72 \%$ in 2010 .

Second, social enterprisers are run in the governmentdependent system in which business loss is replenished by funds from the government or local government. Looking at the sales and profits structure of social businesses, it is shown that the operating loss hit $23.7 \%$ compared with the sales as of 2009 and the support funds from the government or local government took up $35.7 \%$, exceeding the business loss. Such results reveal that funds and donations from government, local government and businesses increased whereas the weight of business profits gradually decreased, recording that it went down to negative (-) as of the end of 2009.

Third, although the requirement for the certification hampering the expansion of social enterprises will be different from forms of businesses, generally employment rate (offering jobs) and offering rate for social service to the vulnerable should be over $30 \%$. That is, the organizations which satisfy the requirement are certified as social enterprises (9 of Enforcement of Ordinance of Item 3 of Paragraph 1 of Article 8 of Social Enterprise Promotion Act).

\subsection{The Problem of Promoting Social Entrepreneur}

The government's social enterprise policy establishes short-sighted policy implication for short-term goal and promotion strategy. As such a short-term objective, the government attempts to foster 1,000 social enterprises and create 50,000 jobs until 2012. As a promotion strategy to accomplish these goals, the local governments take lead and the central government backs up behind, improving the promotion system for incubating social enterprises.

Nevertheless, such short-term policy should be converted from a government lead project to a marketfriendly system; it is pointed out that it must change its direction from the European-type social enterprise promotion developed in private sector to the policy of discovering and fostering social entrepreneur specialized for each region.

As a result, the analytical results for problems and satisfaction appeared in operating program for promoting social enterpriser are as follows.

\subsection{Analysis of Satisfaction of Participants in Academy of Social Entrepreneur}

Undertaking of academy of social entrepreneur is comprised of 10 general courses and 8 expert courses 
from August to November 2010, in form of consortiums including college, private organizations and incorporated associations ( $\mathrm{Yu}, 2011)$.

First, overall satisfaction on the curriculum registers $79.1 \%$ and it can't be said to be high degree due to the characteristics of education. However, the one for expert courses was $83.9 \%$, somewhat higher than general courses.

As causes of dissatisfaction with curriculum, a lack of working-level contents $(16.3 \%)$, inappropriateness of education period $(15.1 \%)$ are $31.4 \%$ of total, meaning that effective contents and schedules must be considered when designing curriculum. Also, as causes of dissatisfactions with general courses, a lot of repeated contents (13.3\%) and a lack of expertise $(11.2 \%)$ are in question and as causes of dissatisfaction in expert courses are inadequateness of education period (22.6\%) and repetition of contents $(12.9 \%)$.

Second, in the satisfaction analysis on participants in education parts for which they want to re-take afterwards, as the courses for retake, founding of a firm was $34.9 \%$; research was $10.5 \%$, indicating that the areas participants could utilize in practice were needed to establish more.

Third, in the analysis of wishes when taking expert courses in the future, as a wish for taking expert courses, specialized courses for industrial classification (30.2\%), the course according to type of work/position/level of participants (18.6\%), networking among those who completed the courses $(17.4 \%)$ and training centered on successful cases in and outside countries in the order, showing that the desire for curriculum which can be utilized practically is high.

To sum up the results of analysis of satisfaction of participants in academy programs for incubation of social enterprisers, they prefer expert courses to general ones and desire the courses specialized for industrial classification so that they can apply them in founding or working level after completing the curriculum.

\subsection{Integrated Evaluation Related with the Extant Academy Operation}

First, the problem related with academy of social enterpriser is that the improvement in general courses for achieving goal of expanding the base for social enterprise needs to establish academy appropriate for specialized courses for each region Also, expert courses have objective of intensive education for subjects and type of businesses and improvement of actual founding and executive operating ability; specialized education not only needs discovering specialized training institutes and developing specialized programs, but also supplement with common evaluation criteria and detailed guideline which enables handling of management and operation.

Second, for specific programs and details related with the education, recruitment of attendee according to the purpose of the education and detailed education guideline with subdivision of education hours which should be essentially reflected is need. It can be also pointed out that overall system construction and management are needed so that follow-up controls can be operated in networking for each agency through reinforcing mutual networking among instructors and continually connecting with attendees.

\subsection{The Limit of Present Support System for Social Enterprise}

First, it's the government's choosy certification for social enterprise. Social enterprise must be equipped with certification conditions appropriate for realization of social purpose of Ministry of Employment and Labor. That is, the social enterprise the government certifies has a limit to weaken identity of it when the increase of government burden (=budget/the responsibility about the result of certification) and financial integrity are not sufficient.

Second, it is criticized that inefficiency of promotion of social enterpriser occurs because a lack of expertise of the intermediate supporting organizations necessary for fostering social enterprisers, restriction in formal consultation and amplification of complaints on site impede promotion of social enterprisers and the effort to reinforce ability of operating bodies is insufficient.

Therefore, it's the problem that sustainability of social enterprise is attenuated despite the government's support policy for promoting social enterpriser. In other words, since moral hazard of operating subjects or education participants who are commissioned for academy program or promoting of young adults social entrepreneurs appears, management and monitoring for commissioned education agencies are needed and it should be compulsory for founders of social enterprises or those who completed the education courses to attend and finish academy for social enterpriser.

\subsection{The Direction of Development of Incubation of Social Entrepreneur}

In this study, it is pointed out that social entrepreneur is the greatest variable that decides the success or failure of social enterprise. That is, promoting social enterprises which preferentially pursue social purpose and incubating social entrepreneur will realize the social 
objectives which provide jobs for the vulnerable and make good occupations to provide social service.

So far, promotions of social enterprisers in Korea had high level of dependence on government funding and it is true that specialized agencies for fostering social enterprisers have been insufficient. In such process, promotion of social enterprisers in Korea which began at the end of 2010, not only secured many commissioned operating agencies but also retained 1.12 billion won of government budget for promoting social enterprisers in 2011.

It has been difficult to get profitable outcomes because of the lack of history about incubating social enterprisers and government budget. In order to foster experts with the spirit of competent social entrepreneurship in the future, it must be noted that the above problems need to be supplemented.

\section{RESULTS AND DISCUSSION}

Through this study, I am concerned whether government's leading policy should take precedence or it must be changed into market-driven policy in fostering social entrepreneur. In other words, government-led policy planning and execution have achieved effects so far. However, it is noted that the role of government needs to supplement flaws of functions of market in promoting social enterprise and entrepreneur.

The government focuses on such policy directions, but it's doubted that it can suggest standard model for incubating social entrepreneur. Thus, the result of this study is expected to be used as a basic material to propose the direction of policy for measure of support of related departments and establishing policy implications centered on social entrepreneur.

\section{CONCLUSION}

The history of social enterprise in Korea is very short. Nevertheless, the social businesses in Korea, not like the development models developed in Europe and the US, accomplished a remarkable growth through our unique government-driven policy. As seen in the problems in the above, however, policies of social enterprise must be converted to the direction that supports ecosystem of social enterprises instead of supporting the social enterprises themselves. In order to properly stimulate social enterprises, it's important to foster social entrepreneurs who will lead social enterprises. The government acknowledges such limit well, empathizing the idea that the policy direction should be changed.

In this study, it is pointed out that social entrepreneur is the greatest variable that decides the success or failure of social enterprise. That is, promoting social enterprises which preferentially pursue social purpose and incubating social entrepreneur will realize the social objectives which provide jobs for the vulnerable and make good occupations to provide social service.

As we have seen in the above, Korea has a unique social entrepreneur promotion policy. The majority of fostering and education programs for social entrepreneur in Korea is still in the level of simple learning, lectures or on-job experiences, which are in the beginning level and participation rate on such education programs are estimated to be low. Therefore, Therefore With the longterm perspective, it is needed to render policy and specialization for fostering Korean-model social entrepreneurs, which is able to raise competent social entrepreneurs suitable for each stage of growth such as sourcing, incubation and launching social entrepreneurs.

Therefore, based on the findings of this study, policy implications are as follows: first, it's necessary to modify and supplement the government policy direction towards incubation of social entrepreneur. To solve such problem, the government fund related with promoting social enterprise should get out of labor cost-centered one and convert into the support centered on ecology or projects and it should put emphasis on follow-up control and evaluation to reduce moral hazard.

Second, the government must suggest a standard model for promotion of social entrepreneur, which has been pointed as a problem. Here standard model means not only standardized education programs and contents according to projects, types and regional governments, but also reducing the projects which can't produce good performance and improving as an education model appropriate for a new environment and changes through appointing professional instructors and business evaluations. The education programs and contents made by such standard model will enhance the expertise and effectiveness of fostering social entrepreneur.

Third, it's essential to suggest specific guideline for detailed educational operation according to education trainees and objectives in promoting social entrepreneur. That is, the satisfaction of the participants of the program should be analyzed to have specialized courses for detailed educational operation which reflect the cause of dissatisfaction on the curriculum, courses the trainees want to re-take and desires when taking expert 
courses, integrating common evaluation criteria and operation of the program.

Fourth, it can be pointed out that interactive networking among instructors should be reinforced through developing and spreading of contents responding to various educational needs and construction and management of general system in which following-up controls of each education agency are possible through continuous connecting with trainees. The educational needs towards social enterprise are intensified day by day whereas contents, materials for lectures, network and following-up controls are below the level we expected. Therefore, it's more needed to develop and propagate various contents by reinforcing support for founding, management and case studies specialized in social enterprise.

Finally, it's more essential to spread awareness of social economy connecting to the promotion of social entrepreneur. Social economy is the foundation for social enterprise to be founded and active. Without the proliferation of social economy, social entrepreneur promotion can only be fostering functionalists and technicians, so the change in social perception is needed. Especially, the lack of expertise of intermediate support organizations necessary for fostering social entrepreneur, limits of formal consultations and amplification of complaints in the field would impede the promotion of social entrepreneur and it was also noted that such drawbacks cause inefficiency of incubating social entrepreneur and efforts to strengthen capability of the operating body is unsatisfactory.

\section{ACKNOWLEDGEMENTS}

This study was supported by the Konkuk University Research Fund.

\section{REFERENCES}

Chang, E.S., 2010. Policy alternative for promotion of sustainable social enterprise. Materials of National Assembly Policy Debate for Vitalization of Social Enterprise.

Kim, E.S., 2011a. Social enterprise and the role of government. Gyeonggi Research Institute.

Kim, S.K., 2011b. Developments of programs to raise social entrepreneur and manual should be tied with, NaEconomy. KDI Information Center.

KSEPA, 2011. Happy to share warm companies and social enterprises to support. Korea Social Enterprise Promotion Agency.

MEL, 2010a. The government's role and task for promotion of social entrepreneur. Proceedings of the Social Entrepreneurship International Conference, (SEIC' 10), Korea Development Institute (KDI).

MEL, 2010b. Fostering creative young adults as social entrepreneur.

MEL, 2011. Ways to vitalize social enterprise.

Odgen-Newton, A., 2010. Social Enterprise in the UK. Proceedings of the International Symposium on Assistance Policy for Social Enterprise, (APSE' 10), Gyeonggi Welfare Foundation and Forum on Social Enterprise Activation.

Schumpeter, J.A., 1994. Capitalism, Socialism and Democracy. 5th Edn., Routledge, ISBN-10: 0415107628, pp: 437.

$\mathrm{SN}, 2011$. Social enterprises have controversy of wasting money. Saejeonbuk News.

Yu, J.K., 2011. The present conditions and actual state of social entrepreneur. Proceedings of the Material from Expert Consultation Conference, (ECC' 11), Korea Research Institute for Vocational Education and Training. 